\title{
Which type 2 diabetes mellitus patients should be screened for subclinical Cushing's syndrome?
}

\author{
Güven Barış Cansu, ${ }^{1}$ Sevgi Atılgan, ${ }^{2}$ Mustafa Kemal Balcı, ${ }^{3}$ \\ Ramazan Sarı, ${ }^{3}$ Sebahat Özdem, ${ }^{4}$ Hasan Ali Altunbaş ${ }^{3}$
}

${ }^{1}$ Division of Endocrinology and Metabolism, Yunusemre State Hospital, Eskişehir; ${ }^{2}$ Division of Endocrinology and Metabolism, Atatürk State Hospital, Antalya; ${ }^{3}$ Division of Endocrinology and Metabolism, Akdeniz University, School of Medicine, Antalya; ${ }^{4}$ Department of Biochemistry, Akdeniz University, School of Medicine, Antalya; Turkey

\begin{abstract}
OBJECTIVE: Diabetes or impaired glucose tolerance are common in patients with Cushing's syndrome (CS). In this study we investigated the incidence of subclinical Cushing's syndrome (SCS) in type 2 diabetic patients with poor and good metabolic control and the relationship between blood glucose and cortisol levels. DESIGN: A total of 400 type 2 diabetes mellitus (T2DM) patients (Group A, HbA1c $\geq 8 \%, n=250$; Group B, HbA1c $\leq 6.5 \%, n=150$ ) were included in the study. Biochemical tests followed by the $1 \mathrm{mg}$ dexamethasone suppression test (DST) were performed. If post-DST cortisol levels were above $1.8 \mu \mathrm{g} / \mathrm{dl}$ (non-suppressed group), the $2 \mathrm{mg}$ DST test was performed for 2 days. Among the patients, post-DST cortisol of at least 1.8 $\mu \mathrm{g} / \mathrm{dL}$ and midnight serum cortisol levels of at least $7.5 \mu \mathrm{g} / \mathrm{dL}$ confirmed the diagnosis of CS. RESULTS: While SCS was observed in 5 patients (2\%) in Group A, no case was observed in group B. There was a statistically significant difference between groups for basal cortisol and post-DST cortisol results ( $\mathbf{p}<\mathbf{0 . 0 0 1}$ and $\mathbf{p}<\mathbf{0 . 0 0 1}$, respectively). Microvascular complication rates were higher in the non-suppressed group $(\mathrm{p}=\mathbf{0 . 0 0 7})$. Post-DST cortisol levels had a positive correlation with the number of complications and HbA1c levels (respectively $r=0.213, p<0.001$, and $\mathrm{r}=0.191, \mathrm{p}<0.001$ ). Multivariate regression analysis revealed that durations of $\mathrm{DM}, \mathrm{HbA1c}$ level, and post $1 \mathrm{mg}$ DST cortisol levels were associated with the number of complications. CONCLUSIONS: This study shows the presence of SCS in a notable number in T2DM patients having poor metabolic control. Screening with $1 \mathrm{mg}$ and $2 \mathrm{mg}$ DST of T2DM patients with poor metabolic control who are also obese and hypertensive and have microvascular complications may be an appropriate method for detection of SCS.
\end{abstract}

Key words: Hypercortisolism, Screening, Subclinical Cushing's syndrome, Type 2 diabetes mellitus

Address for correspondence:

Güven Barış Cansu, MD, Division of Endocrinology and

Metabolism Uluönder Mah, Yunusemre State Hospital,

Salih Bozok Cad, No:23 Tepebaşı/Eskişehir, TR-26190, Turkey;

Tel.: +90 22221195 95, Fax: +90 22233520 41,

E-mail: bcansu74@hotmail.com

Received: 25-10-2016, Accepted: 30-01-2017

\section{INTRODUCTION}

The prevalence of type 2 diabetes mellitus (T2DM) is $30-60 \%$ and of impaired glucose tolerance is $20-50 \%$ in Cushing's Syndrome (CS), which is characterized by hypercortisolism. ${ }^{1,2}$ Hypercortisolism causes hy- 
perglycemia by increasing hepatic gluconeogenesis and causing insulin resistance. Despite this close relationship between hypercortisolism and T2DM, data are limited on the prevalence of CS in diabetic patients. While the incidence of overt CS is reported to be $10-15$ cases per million in various European studies, ${ }^{3,4}$ the ratio increases to $9.4 \%$ in diabetic patients. ${ }^{5-7}$ Most of the patients identified in the studies had subclinical (not overt) CS.

Subclinical Cushing's Syndrome (SCS) is a condition of biochemical cortisol excess such that affected individuals do not present with the classical signs and symptoms of clinically apparent CS. ${ }^{8}$ Patients with SCS and T2DM share common features, including central obesity, hypertension (HT), insulin resistance, and dyslipidemia. This is probably the underlying reason for the fact that SCS is overlooked and underreported. In recent years there has been an increase in the number of published reports emphasizing the necessity of routine SCS screening in diabetic patients, this possibly being especially beneficial in hospitalized T2DM, ${ }^{7,9}$ though it is otherwise not deemed necessary. ${ }^{10}$ However, SCS screening is widely accepted if clinical features are suggestive of CS and resistant HT or hyperglycemia is evident. ${ }^{11}$

In this study, we aimed to investigate the frequency of SCS in T2DM patients admitted to our clinics who had poor blood glucose control but lacked the classical clinical features of overt hypercortisolism.

\section{MATERIALS AND METHODS}

\section{Patients}

The study was conducted in outpatients who met all inclusion criteria and did not fulfill any of the exclusion criteria at the outpatient Department of Endocrinology and Metabolic Diseases at Akdeniz University, Hospital of Medical Faculty, Antalya, Turkey. The study included 250 patients in the study group (Group A, 250 patients, $\mathrm{HbA} 1 \mathrm{c} \geq 8 \%$, poor metabolic control group) and 150 patients in the control group who were similar in age, sex, and body mass index (BMI) (Group B, HbA1c level $\leq 6.5 \%$, good metabolic control). Inclusion criteria were as follows: (1) age $>40$ years; (2) having T2DM for at least 2 years; (3) taking oral antidiabetic (OAD) drugs and/ or insulin; (4) being obese or overweight (BMI $\geq 25$ $\left.\mathrm{kg} / \mathrm{m}^{2}\right)$. Patients meeting any of the following criteria were excluded: (1) using exogenous glucocorticoids currently or within the past 3 months; (2) taking oral contraceptives, antidepressants, antipsychotics, carbamazepine, rifampicin, ketoconazole, desmopressin, and mifepristol or similar drugs that have an effect on cortisol levels or metabolism; (3) patients with depression, chronic renal failure, hepatic failure or dementia; alcoholics, pregnant or breastfeeding patients; (4) those having any acute diseases or malignant diseases; (5) HbA1c $>8 \%$ but not on any treatment; (6) those with overt CS symptoms (moon face, striae, ecchymosis, buffalo hump, etc.); (7) those having a bad sleep-wake cycle.

Time of T2DM onset, ongoing medications, height, weight, waist circumference, and blood pressure of all subjects were recorded. Through clinical and laboratory tests, all subjects were evaluated for microvascular (diabetic retinopathy, nephropathy, and polyneuropathy) and macrovascular complications (coronary, cerebral, peripheral arterial disease). A spot urine albumin-to-creatinine ratio of $>30 \mathrm{mg} / \mathrm{g}$ creatinine was considered to be diagnostic of diabetic nephropathy. Based on the fundus examination of the patients, presence of background retinopathy and advanced fundus changes were considered to be diagnostic of diabetic retinopathy. Polyneuropathy was assessed by using a 10-g monofilament, pinprick sensation, and ankle reflexes test. One or more abnormal findings in these tests were considered to be diagnostic of diabetic polyneuropathy. Those receiving an antihypertensive therapy or having arterial blood pressure $\geq 140 / 90$ $\mathrm{mmHg}$ on two successive measurements performed with a half-hour interval were defined as hypertensive. Subjects with a LDL-cholesterol (LDL-C) level of $>100 \mathrm{mg} / \mathrm{dL}$ or triglyceride (TG) level of $>150 \mathrm{mg} /$ $\mathrm{dL}$ and HDL-cholesterol (HDL-C) level of $<40 \mathrm{mg}$ / $\mathrm{dL}$ (male) and $50 \mathrm{mg} / \mathrm{dL}$ (female) or receiving lipid lowering medication were defined as dyslipidemic.

Local ethics committee approval was obtained for the study. Written informed consent was obtained from all subjects. This study was performed according to the criteria set out by the Declaration of Helsinki.

\section{The study protocol}

Among the patients who agreed to participate, fasting blood glucose (FPG), postprandial blood glu- 
cose (PPG), total cholesterol (TC), HDL-C, LDL-C levels, creatinine, alanine aminotransferase (ALT), urinalysis results, amount of spot urinary albumin and creatinine, and complete blood count values were recorded. The $1 \mathrm{mg}$ overnight dexamethasone suppression test (DST) was performed in all patients. To this end, $1 \mathrm{mg}$ dexamethasone was administered orally at 23:00. Blood samples for plasma cortisol levels were collected at 8:00 in the morning after fasting for at least 12 hours. A repeated 2-day $2 \mathrm{mg}$ DST testing was performed in subjects with plasma cortisol levels that did not fall below $1.8 \mu \mathrm{g} / \mathrm{dL}$. For this purpose, $0.5 \mathrm{mg}$ dexamethasone was given at 6:00, $12: 00,18: 00$, and 24:00 for 2 days. On day 3, blood samples for plasma cortisol were drawn at 8:00. ${ }^{12}$ In the event that cortisol levels remained above $1.8 \mu \mathrm{g} /$ $\mathrm{dL}$, to determine diurnal rhythm disturbances; midnight blood samples for plasma cortisol were analyzed. Blood sampling for midnight cortisol was obtained in a nonsleeping state at 23:00. Cortisol values of $7.5 \mathrm{mg} / \mathrm{dL}$ and above confirmed CS. ${ }^{13}$ Subsequently, blood samples were taken at 8:00 in the morning for adrenocorticotropic hormone (ACTH) and plasma cortisol measurements. According to ACTH levels, pituitary magnetic resonance imaging (MRI) or adrenal computed tomography (CT) was performed. An 8 mg DST was then performed in order to differentiate Cushing's disease from adrenal Cushing's in patients with low/normal plasma ACTH levels. ${ }^{14}$ The study design is shown in Figure 1.

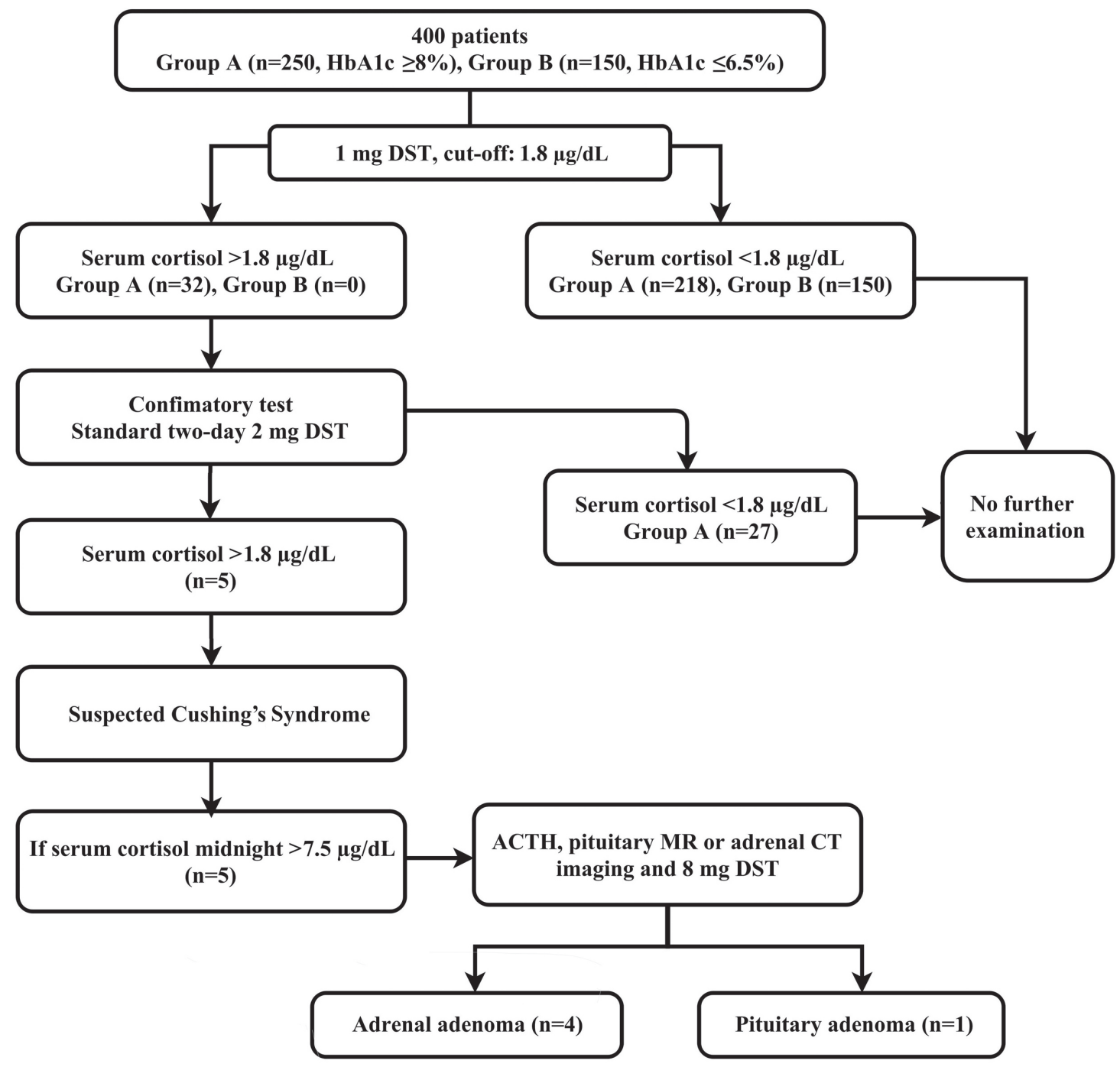

Figure 1. Study design. 
HbA1c levels were measured by a turbidimetric inhibition immunoassay in a Roche Modular PP autoanalyzer. Serum LDL-C was calculated by the Friedwald formula. ${ }^{15}$ ACTH levels were analyzed using the immunoradiometric (IRMA) method (CIS Bio International ORIS Group, France). Plasma cortisol levels were assayed by the electrochemiluminescence immunoassays (ECLIA) method using the Roche E170 (Elecsys module) Immunoassay analyzer with an Elecsys Cortisol (Roche) kit. The measuring range with this kit was defined as $0.018-63 \mu \mathrm{g} / \mathrm{dL}$. Microalbumin level was measured by the Roche Modular PPI biochemical autoanalyzer with the turbidimetric method using benzethonium chloride.

\section{Statistical analysis}

Statistical analysis was performed with SPSS version 20.0 software. Normal distribution was assessed by the Kolmogorov-Smirnov one-sample test. Continuous variables were expressed as mean \pm standard deviation (min-max), and categorical variables were expressed as frequency and percentage. Differences between the two groups were detected using the unpaired Student's t-test or the Mann Whitney U-test for continuous variables and the $\chi^{2}$ test and Fisher's exact test (when appropriate) for categorical variables. Pearson and Spearman's rho tests were used for the correlation analysis. The multiple regression analysis was used to determine whether there was a correlation between the presence of microvascular complications and other parameters in the entire study group. While the presence of microvascular complications was considered as the dependent variable, independent variables were age, gender, duration of diabetes, HbAlc level, presence of HT and HL, BMI, and whether suppression could be achieved using 1 mg DST, each of which is a factor that may play a role in the development of such complications. With a $95 \%$ confidence interval, a $p$ value of less than 0.05 was regarded as statistically significant.

\section{RESULTS}

In group A patients [ 130 females (52\%), 120 males (48\%); mean age, 56 \pm (41-78) years], FBG, PPG, HbAlc, basal cortisol, and post $1 \mathrm{mg}$ DST cortisol levels were higher than those of group B patients [80 females (53\%), 70 males (47\%); mean age, 56 \pm 7
(40-73) years]. Clinical and laboratory comparisons between the two groups are shown in Table 1.

While there was suppression in all patients in group $\mathrm{B}$, no suppression was observed in 32 patients of group A (12.8\%). When suppressed (218 patients) and nonsuppressed (32) patients of group A were compared, the non-suppressed sub-group was seen to have a higher mean age $(\mathrm{p}=0.004)$. Moreover, neuropathy, retinopathy, and polyneuropathy were more common in the non-suppressed group $(\mathrm{p}=0.023, \mathrm{p}=0.029$, and $\mathrm{p}=0.005$, respectively). Basal cortisol and post DST cortisol levels were higher in non-suppressed patients $(p<0.001)$. There was no difference among other compared parameters (Table 2). In group A, correlation analysis revealed that post DST cortisol levels had a positive correlation with the number of complications and $\mathrm{HbA} 1 \mathrm{c}$ levels (respectively $\mathrm{r}=0.213, \mathrm{p}<0.001$, and $\mathrm{r}=0.191, \mathrm{p}<0.001)$. In addition, basal cortisol levels positively correlated with FPG, PPG, and $\mathrm{HbA} 1 \mathrm{c}$ levels (respectively $r=0.171, p=0.007 ; r=0.179$, $p$ $<0.001$ and $\mathrm{r}=0.182, \mathrm{p}<0.001)$. In the multivariate regression analysis, durations of $\mathrm{DM}, \mathrm{HbA} 1 \mathrm{c}$ level, and post $1 \mathrm{mg}$ DST cortisol levels were associated with the number of complications, after adjusting for other potential confounders $(p=0.016, p<0.001$, and $\mathrm{p}=0.002$, respectively). Details are given in Table 3 .

When the participants were evaluated for microvascular complications (retinopathy, nephropathy, and polyneuropathy) the following conclusions emerged in the group that had suppression with $1 \mathrm{mg}$ DST: 79 (36.2\%) patients had no microvascular complication, whereas $65(29.8 \%)$ had one, 51 (23.4\%) had two, and $23(10.6 \%)$ had three complications. In the non-suppressed group, $3(9.4 \%)$ patients had no complication, whereas $10(31.2 \%)$ had one, $11(34.4 \%)$ had two and $8(25 \%)$ had three complications. When the complication ratios of the groups were compared, higher complication ratios were found in the nonsuppressed group $(\mathrm{p}=0.007)$.

Two-day 2 mg DST was carried out for 32 patients who failed to be suppressed through $1 \mathrm{mg}$ DST (post DST cortisol $>1.8 \mathrm{mg} / \mathrm{dL}$ ). Among these patients, 27 (88\%) had cortisol below $1.8 \mu \mathrm{g} / \mathrm{dL}, 5(12 \%)$ had no suppression ( $2 \%$ of those with poor metabolic control). Among 5 patients non-suppressed with 2-day $2 \mathrm{mg}$ DST, one subject (patient 1) had a pituitary adenoma 
Table 1. Clinical and laboratory characteristics of patients

\begin{tabular}{|c|c|c|c|c|}
\hline & & $\begin{array}{c}\text { Group A (HbA1c } \geq 8 \%) \\
(n=250)\end{array}$ & $\begin{array}{c}\text { Group B }(\text { HbA1c } \leq 6.5 \%) \\
(n=150)\end{array}$ & $\mathbf{p}$ \\
\hline \multicolumn{2}{|l|}{$\mathrm{F} / \mathrm{M}$} & $130 / 120$ & $80 / 70$ & 0.836 \\
\hline \multicolumn{2}{|l|}{ Age } & $56 \pm 7$ & $56 \pm 7$ & 0.218 \\
\hline \multicolumn{2}{|c|}{ Durations of DM (years) } & $11 \pm 6$ & $10 \pm 5$ & 0.066 \\
\hline \multicolumn{2}{|c|}{ BMI $\left(\mathrm{kg} / \mathrm{m}^{2}\right)$} & $30.5 \pm 3.7$ & $29.8 \pm 3.8$ & 0.073 \\
\hline \multicolumn{2}{|c|}{ Waist circumference $(\mathrm{cm})$} & $104 \pm 8$ & $102 \pm 8$ & 0.088 \\
\hline \multicolumn{2}{|c|}{$\operatorname{HT} n(\%)$} & $191(76.4)$ & $62(41.3)$ & $<0.001$ \\
\hline \multicolumn{2}{|l|}{ HL n $(\%)$} & $177(70.8)$ & $70(46.7)$ & $<0.001$ \\
\hline \multicolumn{2}{|l|}{ CAD n $(\%)$} & $62(24.8)$ & $25(16.7)$ & 0.061 \\
\hline \multirow[t]{3}{*}{ Treatment } & Insulin $\mathrm{n}(\%)$ & $40(16)$ & $9(6)$ & \\
\hline & OAD n $(\%)$ & $125(50)$ & $109(72.7)$ & \\
\hline & OAD plus Insulin $n(\%)$ & $85(34)$ & $32(21.3)$ & \\
\hline \multicolumn{2}{|c|}{ Nephropathy n (\%) } & $132(52.8)$ & $16(10.7)$ & $<0.001$ \\
\hline \multicolumn{2}{|c|}{ Retinopathy n (\%) } & $88(35.2)$ & $16(10.7)$ & $<0.001$ \\
\hline \multicolumn{2}{|c|}{ Polyneuropathy n (\%) } & $70(28)$ & $14(9.3)$ & $<0.001$ \\
\hline \multicolumn{2}{|c|}{ FBG (mg/dL) } & $199 \pm 59$ & $113 \pm 20$ & $<0.001$ \\
\hline \multicolumn{2}{|c|}{ PPG (mg/dL) } & $274 \pm 84$ & $138 \pm 36$ & $<0.001$ \\
\hline \multicolumn{2}{|c|}{ HbAlc $(\%)$} & $9.5 \pm 1.3$ & $6.1 \pm 0.4$ & $<0.001$ \\
\hline \multicolumn{2}{|c|}{ Basal cortisol $(\mu \mathrm{g} / \mathrm{dL})$} & $16.2 \pm 4.4$ & $14.5 \pm 3.5$ & $<0.001$ \\
\hline \multicolumn{2}{|c|}{ post DST cortisol ( $\mu \mathrm{g} / \mathrm{dL})$} & $1.36 \pm 1.99$ & $0.72 \pm 0.19$ & $<0.001$ \\
\hline
\end{tabular}

Continuous variables are expressed as mean \pm standard deviation and categorical variables are expressed as frequency and percentage. Differences between the two groups were detected using unpaired Student's t-test or the Mann Whitney U-test for continuous variables and the $\chi 2$ test and Fisher's exact test (when appropriate) for categorical variables. Boldfaced data indicate significant results. BMI: body mass index, CAD: coronary artery disease, DM: type 2 diabetes mellitus, DST: dexamethasone suppression test, F: female, FPG: fasting blood glucose, HT: hypertension, HL: hyperlipidemia, M: male, OAD: oral antidiabetic drug, PPG: postprandial blood glucose.

and 4 other subjects (patients 2, 3, 4, and 5) had adrenal adenoma. Clinical and laboratory characteristics of the patients are shown in Table 4.

The patient with Cushing's disease had refused transsphenoidal surgery and received fluconazole therapy in order to inhibit steroidogenesis. The 1 $\mathrm{mg}$ DST revealed adequate cortisol suppression in the 2 nd month of treatment. In 3 of the 4 patients with CS, laparoscopic adrenalectomy was performed successfully and the pathology results were reported as adrenal adenoma. Based on the post-surgically repeated blood analysis, a cure for CS was achieved. The other adrenal adenoma patient refused recommended further evaluation and treatment. Following the surgical treatment, in 3 adrenal adenoma patients and 1 pituitary adenoma patient, the insulin and oral antidiabetic drug dosing they had been using was reduced by approximately $30-40 \%$ and $\mathrm{HbA} 1 \mathrm{c}$ levels significantly improved. In 2 patients, normotension was achieved 4-6 months after surgery, in 1 patient the number of prescribed antihypertensive drugs was decreased from 2 to 1 .

\section{DISCUSSION}

In this study involving patients with T2DM, 5 patients $(2 \%)$ had SCS with poor metabolic control, while no SCS was detected in patients with good metabolic control. In the literature, there are a number of studies investigating the prevalence of SCS in patients with T2DM (Table 5). These studies used the overnight $1 \mathrm{mg}$ DST test, ${ }^{5-7,16-20}$ late-night salivary cortisol (NLSC) ${ }^{10,21-23}$ or both in combination ${ }^{24}$ and found a SCS prevalence rate ranging from 0 to $9.4 \%$. The varying prevalence rates documented by these studies may arise from the differences among the studies, such as different study designs, not using 
Table 2. Comparison of $1 \mathrm{mg}$ DST suppressed and non-suppressed in group A

\begin{tabular}{|c|c|c|c|}
\hline & $\begin{array}{l}\text { Patients that had suppression } \\
\text { with } 1 \text { mg DST (n=218) } \\
\text { (Suppressed group) }\end{array}$ & $\begin{array}{l}\text { Patients that did not have suppression } \\
\text { with } 1 \text { mg DST }(\mathrm{n}=32) \\
\text { (Non-suppressed group) }\end{array}$ & $\mathbf{p}$ \\
\hline $\mathrm{F} / \mathrm{M}$ & $113 / 105$ & $17 / 15$ & 0.836 \\
\hline Age & $56 \pm 7$ & $60 \pm 7$ & 0.004 \\
\hline Durations of DM (years) & $11 \pm 5$ & $12 \pm 6$ & 0.389 \\
\hline $\operatorname{BMI}\left(\mathrm{kg} / \mathrm{m}^{2}\right)$ & $30.6 \pm 3.9$ & $30 \pm 2.8$ & 0.269 \\
\hline Waist circumference $(\mathrm{cm})$ & $103 \pm 8$ & $105 \pm 7$ & 0.225 \\
\hline $\operatorname{HT~n~}(\%)$ & $165(75.7)$ & $26(81.3)$ & 0.656 \\
\hline HL n $(\%)$ & $153(70.2)$ & $24(75)$ & 0.680 \\
\hline Nephropathy n (\%) & $109(50)$ & $23(71.9)$ & 0.023 \\
\hline Retinopathy n (\%) & $71(32.6)$ & $17(53.1)$ & 0.029 \\
\hline Polyeuropathy n (\%) & $54(24.8)$ & $16(50)$ & 0.005 \\
\hline $\mathrm{FBG}(\mathrm{mg} / \mathrm{dL})$ & $202 \pm 58$ & $181 \pm 61$ & 0.066 \\
\hline PPG (mg/dL) & $275 \pm 83$ & $262 \pm 90$ & 0.407 \\
\hline HbAlc $(\%)$ & $9.5 \pm 1.3$ & $9.4 \pm 1.1$ & 0.603 \\
\hline Basal cortisol $(\mu \mathrm{g} / \mathrm{dL})$ & $15.7 \pm 4.3$ & $19.5 \pm 4.3$ & $<0.001$ \\
\hline post DST cortisol $(\mu \mathrm{g} / \mathrm{dL})$ & $0.86 \pm 0.31$ & $4.68 \pm 4.19$ & $<0.001$ \\
\hline
\end{tabular}

Continuous variables are expressed as mean \pm standard deviation and categorical variables are expressed as frequency and percentage. Differences between the two groups were detected using unpaired Student's t-test or the Mann Whitney U-test for continuous variables and the $\chi 2$ test and Fisher's exact test (when appropriate) for categorical variables. Boldfaced data indicate significant results. BMI: body mass index, DM: diabetes mellitus, DST: dexamethasone suppression test, F: female, FPG: fasting blood glucose, HT: hypertension, HL: hyperlipidemia, M: male, PPG: postprandial blood glucose.

Table 3. Multivariate regression analysis with presence of microvascular complications as dependent variables. All participants $(n=400)$

\begin{tabular}{llccc}
\hline & & Beta & $\mathbf{p}$ & $\mathbf{R}^{2}$ \\
\hline Presence of microvascular complications & & & 0.242 \\
& Durations of DM & 0.011 & $\mathbf{0 . 0 1 6}$ & $<0.001$ \\
& HbAlc level & 0.096 & $<$ \\
& Presence of suppression with 1 mg DST & -0.259 & $\mathbf{0 . 0 0 2}$
\end{tabular}

R-square shows the combined effect of the independent variables. Nonpredictive variables are age, gender, presence of HT and HL, and BMI. Boldfaced data indicate significant results.

BMI: body mass index, DM: diabetes mellitus, DST: dexamethasone suppression test, HL: hyperlipidemia, HT: hypertension.

Table 4. Clinical characteristics of Cushing's syndrome patients

\begin{tabular}{|c|c|c|c|c|c|c|c|c|c|c|c|}
\hline & $\begin{array}{c}\text { Age } \\
\text { (years) }\end{array}$ & Comorbidity & $\begin{array}{c}\text { Diabetic } \\
\text { complication }\end{array}$ & Treatment & $\begin{array}{c}\text { Basal } \\
\text { cortisol } \\
(\mu \mathrm{g} / \mathrm{dL})\end{array}$ & $\begin{array}{c}1 \mathrm{mg} \\
\mathrm{DST} \\
(\mu \mathrm{g} / \mathrm{dL})\end{array}$ & $\begin{array}{c}\text { 2-day } \\
2 \mathrm{mg} \\
\text { DST } \\
(\mu \mathrm{g} / \mathrm{dL})\end{array}$ & $\begin{array}{l}\text { ACTH } \\
(\mathrm{pg} / \mathrm{ml})\end{array}$ & $\begin{array}{c}\text { Midnight } \\
\text { cortisol } \\
(23: 00) \\
(\mu \mathrm{g} / \mathrm{dL})\end{array}$ & $\begin{array}{c}8 \mathrm{mg} \\
\text { DST } \\
(\mu \mathrm{g} / \mathrm{dL})\end{array}$ & $\begin{array}{c}\text { CS } \\
\text { etiology }\end{array}$ \\
\hline Patient 1 & 60 & HT, CAD & DRP, DNP & OAD & 23.6 & 3.67 & 5.37 & 113 & 10.3 & 2.67 & PA \\
\hline Patient 2 & 48 & HT, HL & DNP, DPN & $\mathrm{OAD}+\mathrm{INS}$ & 11.3 & 2.89 & 3.7 & 10.4 & 10.5 & 7.02 & AA \\
\hline Patient 3 & 50 & HL & DRP & $\mathrm{OAD}+\mathrm{INS}$ & 13.8 & 6.9 & 9 & 26.2 & 10.1 & 8.65 & AA \\
\hline Patient 4 & 73 & HT, HL, CAD & DRP, DNP, DPN & $\mathrm{OAD}+\mathrm{INS}$ & 10.9 & 2.82 & 2.65 & 10.1 & 8.9 & 6.03 & AA \\
\hline Patient 5 & 66 & HT, HL, CAD & DRP, DPN & $\mathrm{OAD}+\mathrm{INS}$ & 12.4 & 1.99 & 2.09 & 41 & 17.4 & 7.91 & $\mathrm{AA}$ \\
\hline
\end{tabular}

AA: adrenal adenoma, CAD: coronary artery disease, HL: hyperlipidemia, HT: hypertension, DNP: diabetic nephropathy DPN: diabetic polyneuropathy, DRP: diabetic retinopathy, INS: insulin, OAD: oral antidiabetic, PA: pituitary adenoma. 
Table 4. Clinical characteristics of Cushing's syndrome patients

\begin{tabular}{|c|c|c|c|c|c|c|c|c|c|c|c|}
\hline & $\begin{array}{c}\text { Age } \\
\text { (years) }\end{array}$ & Comorbidity & $\begin{array}{c}\text { Diabetic } \\
\text { complication }\end{array}$ & Treatment & $\begin{array}{c}\text { Basal } \\
\text { cortisol } \\
(\mu \mathrm{g} / \mathrm{dL})\end{array}$ & $\begin{array}{c}1 \mathrm{mg} \\
\text { DST } \\
(\mu \mathrm{g} / \mathrm{dL})\end{array}$ & $\begin{array}{c}\text { 2-day } \\
2 \mathrm{mg} \\
\text { DST } \\
(\mu \mathrm{g} / \mathrm{dL})\end{array}$ & $\begin{array}{l}\text { ACTH } \\
(\mathrm{pg} / \mathrm{ml})\end{array}$ & $\begin{array}{c}\text { Midnight } \\
\text { cortisol } \\
(23: 00) \\
(\mu \mathrm{g} / \mathrm{dL})\end{array}$ & $\begin{array}{c}8 \mathrm{mg} \\
\mathrm{DST} \\
(\mu \mathrm{g} / \mathrm{dL})\end{array}$ & $\begin{array}{c}\text { CS } \\
\text { etiology }\end{array}$ \\
\hline Patient 1 & 60 & HT, CAD & DRP, DNP & OAD & 23.6 & 3.67 & 5.37 & 113 & 10.3 & 2.67 & PA \\
\hline Patient 2 & 48 & HT, HL & DNP, DPN & $\mathrm{OAD}+\mathrm{INS}$ & 11.3 & 2.89 & 3.7 & 10.4 & 10.5 & 7.02 & AA \\
\hline Patient 3 & 50 & HL & DRP & $\mathrm{OAD}+\mathrm{INS}$ & 13.8 & 6.9 & 9 & 26.2 & 10.1 & 8.65 & AA \\
\hline Patient 4 & 73 & HT, HL, CAD & DRP, DNP, DPN & $\mathrm{OAD}+\mathrm{INS}$ & 10.9 & 2.82 & 2.65 & 10.1 & 8.9 & 6.03 & AA \\
\hline Patient 5 & 66 & HT, HL, CAD & DRP, DPN & $\mathrm{OAD}+\mathrm{INS}$ & 12.4 & 1.99 & 2.09 & 41 & 17.4 & 7.91 & $\mathrm{AA}$ \\
\hline
\end{tabular}

AA: adrenal adenoma, CAD: coronary artery disease, HL: hyperlipidemia, HT: hypertension, DNP: diabetic nephropathy DPN: diabetic polyneuropathy, DRP: diabetic retinopathy, INS: insulin, OAD: oral antidiabetic, PA: pituitary adenoma.

the same DST cutoff values, whether or not they included patients with cushingoid appearance, the studies being mostly conducted at central hospitals, and the selection of the patient cohort from inpatients or outpatients.

Screening of SCS in T2DM patients has been performed in both inpatients hospitalized for poor metabolic control and outpatients, and quite different results have been obtained. Out of 15 studies, 10 were performed with outpatients (including our study), while 5 were performed with inpatients. SCS prevalence was found to be $0-2.9 \%$ in outpatients and $2-9.4 \%$ in inpatients (Table 5). These results suggest the presence of higher rates of SCS in inpatients. Hospitalization for any reason (poor metabolic control or presence of infection) may indicate a higher possibility of having SCS, and these patients may require further investigation. In our study, the patients included were from an outpatient setting and the SCS rate was $2 \%$, similarly to that recorded in the literature. Although this ratio is quite small, early detection and treatment of SCS, which is characterized by high mortality and morbidity, is important for improving quality of life and life expectancy.

In individuals with T2DM, duration of disease and duration of exposure to high blood glucose is directly proportional to the development of complications. In addition, Oltmanns et al have pointed out that the stimulatory effect of cortisol on hepatic gluconeogenesis exacerbates hyperglycemia and may play a role in the development of diabetes-related complications. ${ }^{25}$ This view was also supported by the findings of various cross-sectional studies showing the relationship between carotid atherosclerosis, retinopathy, and nephropathy caused by increased HPA activity. ${ }^{26-28}$

When we analyzed studies evaluating SCS prevalence in T2DM patients, we found only one study investigating diabetic complications. ${ }^{16}$ In this study, the ratios of patients with diabetic complications were $32 \%$ in retinopathy, $27 \%$ in nephropathy, and $43 \%$ in polyneuropathy; however, in the screening test, complication rates in patients without adequate suppression were not specified. In our study, every patient with SCS had at least one diabetic microvascular complication. In addition, in terms of complication rates, complication rates of patients without suppression with $1 \mathrm{mg}$ DST were higher than those with suppression, this being statistically significant (Table 2). Moreover, the correlation analysis revealed a significant relationship between the numbers of complications and cortisol levels after $1 \mathrm{mg}$ DST. In light of these results, during the patient selection phase of clinical studies, enrollment of patients with complications might be specifically recommended and it may be more appropriate that SCS screening in diabetic patients be recommended to patients with microvascular complications besides poor regulation of blood glucose, obesity, and hypertension.

Recent studies showed $1 \mathrm{mg}$ DST has high false positivity, while screening with NLSC has lower rates of false positivity. ${ }^{22}$ Gagliardi et al, in a study using salivary cortisol as a screening test, used cutoff value of $13 \mathrm{nmol} / \mathrm{L}$ for NLSC and did not find SCS. They reported the false positivity rate for NLSC as $3 \%$. Several other groups have conducted studies comparing $1 \mathrm{mg}$ DST and NLSC. When we examined other 


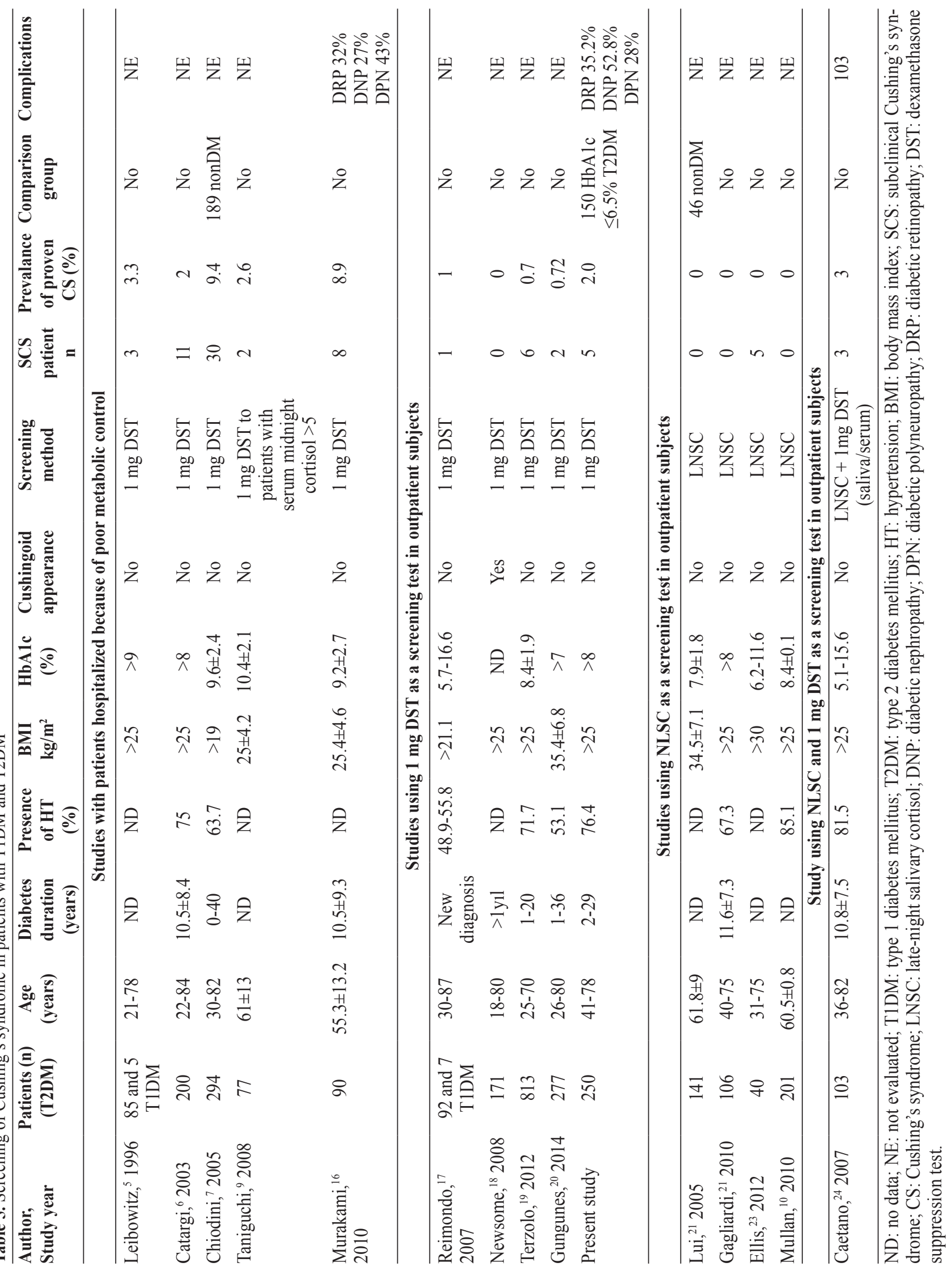




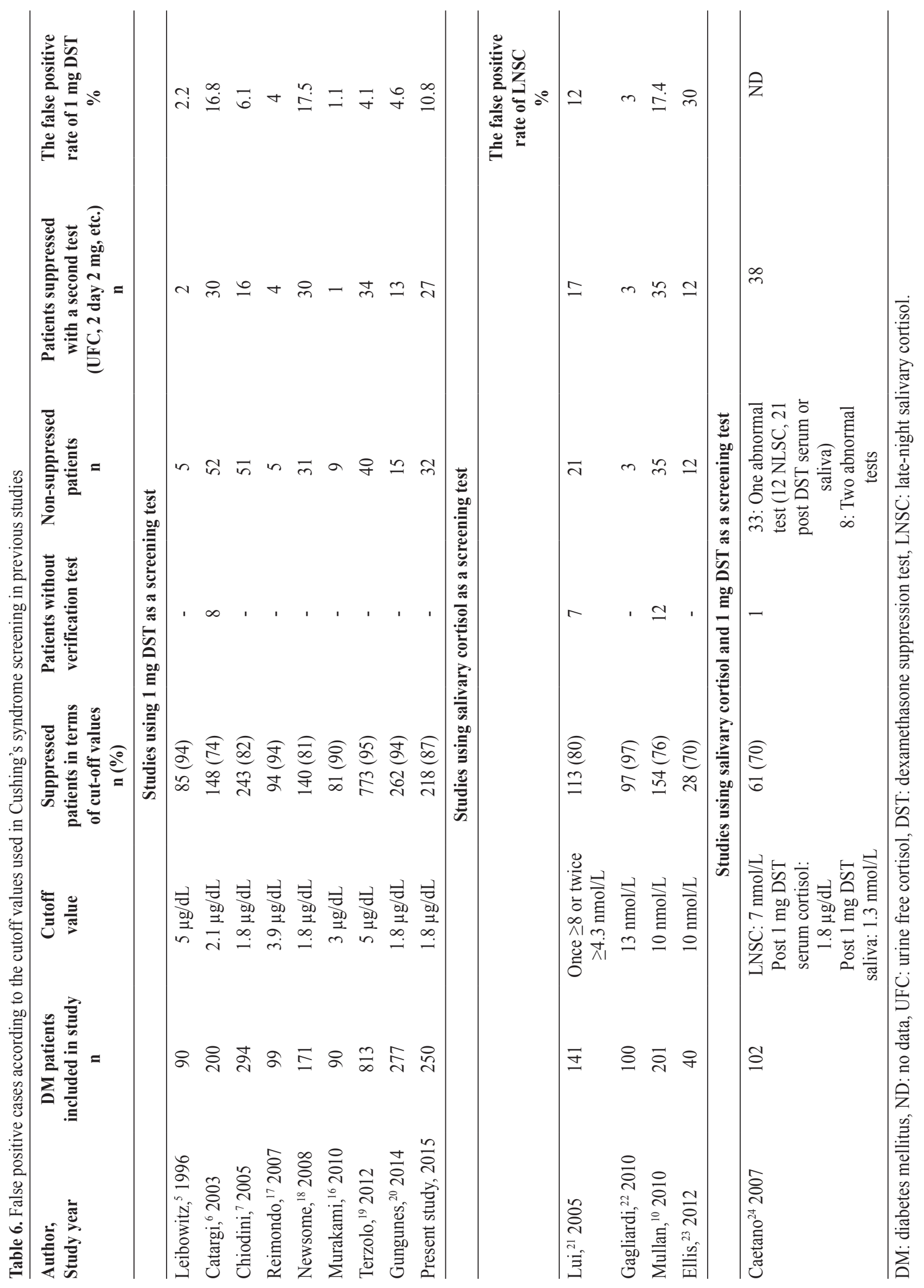


studies using NLSC as a screening test, we see false positivity rates of $12-30 \%$ (Table 6 ). By contrast, in studies performed with $1 \mathrm{mg}$ DST, the false positivity rate ranged between 1.1-17.5\%. In our study, post 1 mg DST cortisol levels of 32 patients among the 250 patients did not fall below $1.8 \mu \mathrm{g} / \mathrm{dL}$ and in 27 of them we achieved suppression with 2-day $2 \mathrm{mg}$ DST (false positivity rate: $10.8 \%$ ). Non-suppression with $1 \mathrm{mg}$ DST and suppression with $2 \mathrm{mg}$ DST may be associated with obesity, higher rates of HT, and high blood glucose levels of the participants. In fact, all of these patients had HbA1c levels above 8 as well as poor metabolic control.

In 2012, Krarup et al assessed 7 prospective, 2 casecontrol, and 2 cross-sectional studies in their review investigating SCS prevalence in T2DM patients. ${ }^{11}$ In this review, the authors indicated that the following three criteria must be fulfilled by the evaluated study to reach scientifically appropriate conclusions.

1) During primary screening, as recommended by the American Endocrine Society, twice 24-hour urine or twice salivary cortisol and once DST must be performed, and in the event of any abnormal result, this should be confirmed by repeating the test or by using one of the other two tests.

2) Studies should include randomly selected diabetic subjects, ideally including individuals with cushingoid appearance.

3) No dropout after a pathological test should be accepted. Only one study fulfilled all three criteria, and the prevalence of SCS was found to be $3.3 \%$ in this study. ${ }^{5}$ In this review, the authors suggested that in T2DM patients with a cushingoid appearance and hypertension, in the presence of truncal obesity or dyslipidemia, screening of hypercortisolism may be performed. Based on the results of our study, we suggest SCS screening in diabetic patients with microvascular complications. In addition, because of its high sensitivity and specificity, the late-night salivary cortisol test may be suitable as a screening test.

However, when we look at the studies in the diabetic population, in only one study was a false positive rate of 3\% identified, while in other studies it ranged from $12-30 \%$ (Table 6). Mullan et al used NLSC as a screening test in diabetic patients, set the cutoff value for NLSC at $10 \mathrm{nmol} / \mathrm{L}$, and found NLSC at more than $10 \mathrm{nmol} / \mathrm{L}$ in 47 out of 201 patients. Of these patients, 35 had further testing with a $1 \mathrm{mg}$ DST and 28 had levels below $2.1 \mu \mathrm{g} / \mathrm{dL}$. The remaining 8 patients achieved suppression with the cutoff value for NLSC as 2-day $2 \mathrm{mg}$ DST and no SCS case was detected. As a result of this study, the researchers do not recommend NLSC in SCS screening in diabetic clinics due to its high false positive rates; nevertheless, they stated that NLSC is applicable in outpatients who have a high risk of SCS. ${ }^{10}$ Considering the data we obtained from this study, despite the high false positive rate of $1 \mathrm{mg}$ DST, 2-day $2 \mathrm{mg}$ DST in nonsuppressors will be more appropriate.

One of the shortcomings of our study was that we did not use 24-hour urinary cortisol levels, while another was that some patients with poor metabolic control did not receive sufficient antidiabetic treatment causing high $\mathrm{HbA} 1 \mathrm{c}$ levels, therefore some patients in the poor metabolic control group should be included after receiving adequate treatment. More than half of the patients were receiving only OAD therapy $(15.9 \%$ intensive insulin therapy, 51\% OAD, and $33.1 \%$ OAD plus insulin). Another limitation of our study might be that we did not enroll patients with clinical findings clearly indicating Cushing's syndrome. We thus may have underestimated the percentage of CS by excluding these patients. Although this is seen as a failure in the selection of patients included in the study, even diagnosing SCS in 5 (2\%) patients among 250 patients was an important rate. If the patient group had been composed of patients receiving adequate treatment, this ratio could have been higher.

\section{CONCLUSION}

In this study, we found that by evaluating the frequency of SCS in T2DM patients, higher SCS prevalence in patients with poor metabolic control was detectable. Screening with $1 \mathrm{mg}$ DST in T2DM patients with poor metabolic control who are obese and hypertensive and with microvascular complications may be an appropriate method for detecting SCS.

\section{FUNDING STATEMENT}

No funding. 


\section{DECLARATION OF INTEREST}

The authors declare that there is no conflict of interest that could be perceived as prejudicing the impartiality of the research reported.

\section{REFERENCES}

1. Boscaro M, Arnaldi G, 2009 Approach to the patient with possible Cushing's syndrome. J Clin Endocrinol Metab 94: 3121-3131.

2. Biering H, Knappe G, Gerl H, Lochs H, 2000 Prevalence of diabetes in acromegaly and Cushing syndrome. Acta Med Austriaca 27: 27-31.

3. Newell-Price J, 2009 Diagnosis/differential diagnosis of Cushing's syndrome: a review of best practice. Best Pract Res Clin Endocrinol Metab 23: Suppl 1: 5-14.

4. Steffensen C, Bak AM, Rubeck KZ, Jorgensen JO, 2010 Epidemiology of Cushing's syndrome. Neuroendocrinology 92: Suppl 1: 1-5.

5. Leibowitz G, Tsur A, Chayen SD, et al, 1996 Pre-clinical Cushing's syndrome: an unexpected frequent cause of poor glycaemic control in obese diabetic patients. Clin Endocrinol (Oxf) 44: 717-722.

6. Catargi B, Rigalleau V, Poussin A, et al, 2003 Occult Cushing's syndrome in type-2 diabetes. J Clin Endocrinol Metab 88: 5808-5813.

7. Chiodini I, Torlontano M, Scillitani A, et al, 2005 Association of subclinical hypercortisolism with type 2 diabetes mellitus: a case-control study in hospitalized patients. Eur J Endocrinol 153: 837-844.

8. Chiodini I, Morelli V, Salcuni AS, et al, 2010 Beneficial metabolic effects of prompt surgical treatment in patients with an adrenal incidentaloma causing biochemical hypercortisolism. J Clin Endocrinol Metab 95: 2736-2745.

9. Taniguchi T, Hamasaki A, Okamoto M, 2008 Subclinical hypercortisolism in hospitalized patients with type 2 diabetes mellitus. Endocr J 55: 429-432.

10. Mullan K, Black N, Thiraviaraj A, et al, 2010 Is there value in routine screening for Cushing's syndrome in patients with diabetes? J Clin Endocrinol Metab 95: 2262-2265.

11. Krarup T, Hagen C, 2012 Do patients with type 2 diabetes mellitus have an increased prevalence of Cushing's syndrome? Diabetes Metab Res Rev 28: 219-227.

12. Arnaldi G, Angeli A, Atkinson AB, et al, 2003 Diagnosis and complications of Cushing's syndrome: a consensus statement. J Clin Endocrinol Metab 88: 5593-5602.

13. Papanicolaou DA, Yanovski JA, Cutler GB, Chrousos GP, Nieman LK, 1998 A single midnight serum cortisol measurement distinguishes Cushing's syndrome from pseudo-Cushing states. J Clin Endocrinol Metab 83: 1163-1167.

14. Meier CA, Biller BM, 1997 Clinical and biochemical evaluation of Cushing's syndrome. Endocrinol Metab
Clin North Am 26: 741-762.

15. Friedewald WT, Levy RI, Fredrickson DS, 1972 Estimation of the concentration of low-density lipoprotein cholesterol in plasma, without use of the preparative ultracentrifuge. Clin Chem 18: 499-502.

16. Murakami H, Nigawara T, Sakihara S, et al, 2010 The frequency of type 2 diabetic patients who meet the endocrinological screening criteria of subclinical Cushing's disease. Endocr J 57: 267-272.

17. Reimondo G, Pia A, Allasino B, et al, 2007 Screening of Cushing's syndrome in adult patients with newly diagnosed diabetes mellitus. Clin Endocrinol (Oxf) 67: 225-229.

18. Newsome S, Chen K, Hoang J, et al, 2008 Cushing's syndrome in a clinic population with diabetes. Intern Med J 38: 178-182.

19. Terzolo M, Reimondo G, Chiodini I, et al, 2012 Screening of Cushing's syndrome in outpatients with type 2 diabetes: results of a prospective multicentric study in Italy. J Clin Endocrinol Metab 97: 3467-3475.

20. Gungunes A, Sahin M, Demirci T, et al, 2014 Cushing's syndrome in type 2 diabetes patients with poor glycemic control. Endocrine 47: 895-900.

21. Liu H, Bravata DM, Cabaccan J, Raff H, Ryzen E, 2005 Elevated late-night salivary cortisol levels in elderly male type 2 diabetic veterans. Clin Endocrinol (Oxf) 63: 642-649.

22. Gagliardi L, Chapman IM, O'Loughlin P, Torpy DJ, 2010 Screening for subclinical Cushing's syndrome in type 2 diabetes mellitus: low false-positive rates with nocturnal salivary cortisol. Horm Metab Res 42: 280-284.

23. Ellis E, Chin PK, Hunt PJ, et al, 2012 Is late-night salivary cortisol a better screening test for possible cortisol excess than standard screening tests in obese patients with Type 2 diabetes? N Z Med J 125: 47-58.

24. Caetano MS, Silva Rdo C, Kater CE, 2007 Increased diagnostic probability of subclinical Cushing's syndrome in a population sample of overweight adult patients with type 2 diabetes mellitus. Arq Bras Endocrinol Metabol 51: 1118-1127.

25. Oltmanns KM, Dodt B, Schultes B, et al, 2006 Cortisol correlates with metabolic disturbances in a population study of type 2 diabetic patients. Eur J Endocrinol 154: 325-331.

26. Tsigos C, Young RJ, White A, 1993 Diabetic neuropathy is associated with increased activity of the hypothalamic-pituitary-adrenal axis. J Clin Endocrinol Metab 76: 554-558.

27. Bhatia RP, Adarsh Singh RH, 1983 Cortisol in diabetic retinopathy. Ann Ophthalmol 15: 128-130.

28. Peppa-Patrikiou M, Scordili M, Antoniou A, et al, 1998 Carotid atherosclerosis in adolescents and young adults with IDDM. Relation to urinary endothelin, albumin, free cortisol, and other factors. Diabetes Care 21: 10041007. 